\title{
The Temperature Distribution of Bathtub
}

\author{
Yuhe $\operatorname{Tian}^{1, \text { a }}$ \\ ${ }^{1}$ North China Electric Power University, Baoding 071000, China \\ atyhstudy@163.com
}

Keywords: the first law of thermo dynamics Fouriers Law, Calorie formula

\begin{abstract}
Fouriers Law and Calorie formula to derive the heat conduction equation and to discuss the temperature of the bathtub water in space and time. Firstly, we set time as a constant. In space, we projected the temperature distribution equation to the three planes : X-Y Plane Y-Z plane and X-Z plane. To solve the equations, the PDE (Partial Differential Equations) toolbox of MATLAB was used. Then we kept the temperature constant, the image of temperature distribution at different time was obtained. The variance of the temperature in the bathtub was defined to measure the temperature distribution.
\end{abstract}

\section{Introduction}

All manuscripts must be in English, also the table and figure texts, otherwise we cannot publish your paper. Please keep a second copy of your manuscript in your office. When receiving the paper, we assume that the corresponding authors grant us the copyright to use the paper for the book or journal in question. Should authors use tables or figures from other Publications, they must ask the corresponding publishers to grant them the right to publish this material in their paper.

It will be very nice to take a long hot bath when you come home with a tired body. However, the bathtub in our bathroom is a simple water containment vessel, in which the water can not keep the constant temperature. So the method was put forward-using a constant trickle of hot water from the faucet to reach the bathing water.In this case, it is necessary to find a best way to maximize both the utilization rate of water and the constant temperature. From the practical considerations, we need to analyze the effect of many factors. Thus we develop a model to show the temperature distribution of the bathtub water in space and time

\section{Temperature Changes with Time and Space}

In order to discuss the temperature of the bathtub water in space and time, we use the first law of thermo dynamics, Fourier's Law and Calorie formula to create a new model.

- the first law of thermodynamics

$$
Q=Q_{1}+Q_{2}
$$

Where Q, Q1 and Q2respectively represent the heat absorbed by temperature change, the heat flowing through the boundary and the heat provided of heat reservior.

- Fourier's Law

$$
d Q=-k(x, y, z) \frac{\partial x}{\partial y} d s d t
$$

Where $\mathrm{k}(\mathrm{x} ; \mathrm{y} ; \mathrm{z})$ represent the thermal transmissivity of material.

- Derivation of the heat comnservation equation

Simply take any $\mathrm{S}$ of a smooth closed surface $\Omega$ in the object $\mathrm{G}$, discussing the heat change law of $\Omega$.The absorded (or released)heat of the temperature of each point in the $\Omega$ changed from u(x; y; $\mathrm{z} ; \mathrm{t} 1)$ to $\mathrm{u}(\mathrm{x} ; \mathrm{y} ; \mathrm{z} ; \mathrm{t} 2)$, shall be equal to the sum of the heat flows into (or out of) $\Omega$ throngh surface $\mathrm{S}$ and the heat provided (or absorption) by heart source during $t_{1}$ to $t_{2}$. 
(1) The heat flows into $\Omega$ throngh surface S (Q1)

Based on Fourier's Law, the heat flows into $\Omega$ throngh surface $S$ during $\mathrm{t} 1$, $\mathrm{t} 2$ is as follows:

$$
Q=\int_{t_{1}}^{t_{2}} \iint_{s} k(x, y, z) \frac{\partial u}{\partial n} d s d t
$$

Based on Gauss Formula

$$
\iiint_{\Omega} \operatorname{div} A d x d y d z=\iint_{S} A n d S_{x}
$$

Q1 is as follows

$$
Q_{2}=\int_{t_{1}}^{t_{2}}\left[\iiint_{\Omega}\left(\frac{\partial}{\partial x}\left(k \frac{\partial u}{\partial x}\right)+\frac{\partial}{\partial Z}\left(k \frac{\partial u}{\partial y}\right)+\frac{\partial}{\partial z}\left(k \frac{\partial u}{\partial z}\right)\right) d V\right] d t
$$

(2) the heat provided (or absorption) by heat source (Q2) during t1 tot2

$$
Q_{1}=\int_{t_{1}}^{t_{2}}\left[\iiint_{\Omega} F(x, y, z, t) d V\right] d t
$$

Where $\mathrm{F}(\mathrm{x} ; \mathrm{y} ; \mathrm{z} ; \mathrm{t})$ represent the intensity of heat source,that is, the quantity of heat released from the unit volume within the unit time.

Finally we get the formula in accordance with our model

$$
\int_{t_{1}}^{t_{2}}\left[\int \int \int _ { \Omega } \left(\frac{\partial}{\partial x}\left(k \frac{\partial u}{\partial x}\right)+\frac{\partial}{\partial y}\left(k \frac{\partial u}{\partial y}\right)+\frac{\partial}{\partial z}\left(k \frac{\partial u}{\partial z}\right)+F(x, y, z, t)\right.\right.
$$

\section{Two-dimensional(2-D) heat conduction equation}

To simplified modelI, we projected the temperature distribution equation to the three plane[1] $\mathrm{X}-\mathrm{Y}$ plane, $\mathrm{Y}-\mathrm{Z}$ plane and $\mathrm{X}-\mathrm{Z}$ plane.

The temperature distribution equation on $\mathrm{X}-\mathrm{Y}$ plane

$$
\frac{\partial U}{\partial t}-k^{2}\left(\frac{\partial^{2} u}{\partial x^{2}}+\frac{\partial^{2} u}{\partial y^{2}}\right)=f(x, y, z)
$$

Boundary Conditions

$$
\left\{\begin{array}{l}
\frac{\partial u}{\partial x}+\frac{\partial u}{\partial x}+\left.h T\right|_{\omega}=h T_{\text {out }} \\
\frac{\partial u}{\partial x}+\left.h T\right|_{x= \pm \frac{b}{2},-\frac{a}{2} \leq y \leq \frac{a}{2}}=h T_{\text {out }} \\
\frac{\partial u}{\partial y}+\left.h T\right|_{y= \pm \frac{a}{2},-\frac{b}{2} \leq y \leq \frac{b}{2}}=h T_{\text {out }}
\end{array}\right.
$$




\section{The temperature distribution on the three plane}
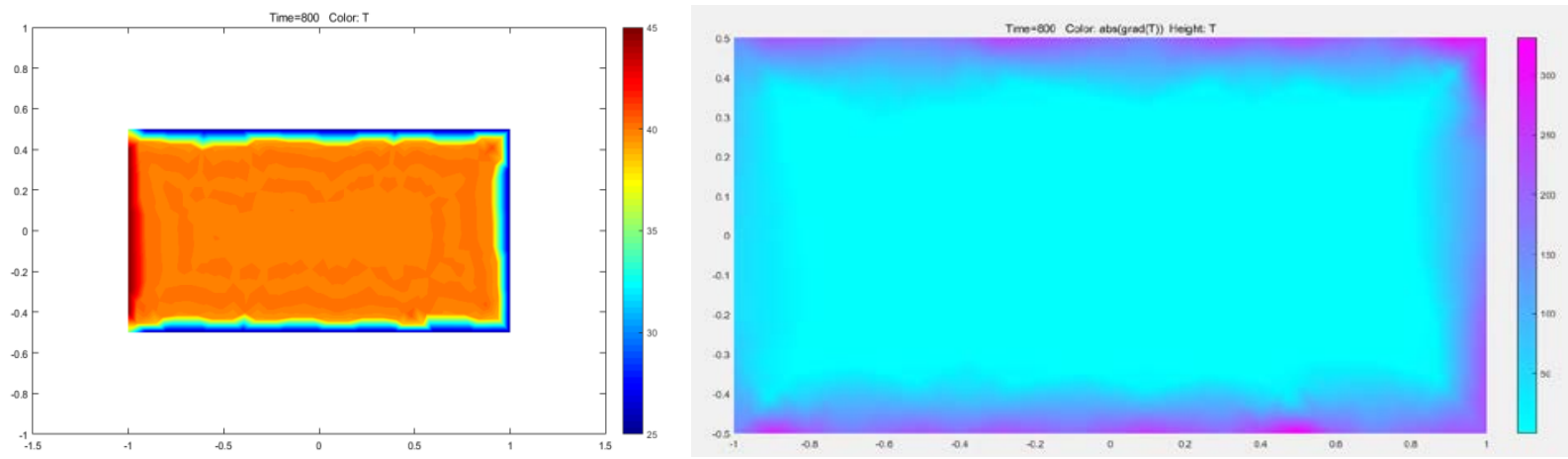

Figure 1: the temperature distribution and gradient on the $\mathrm{X}-\mathrm{Y}$ plane

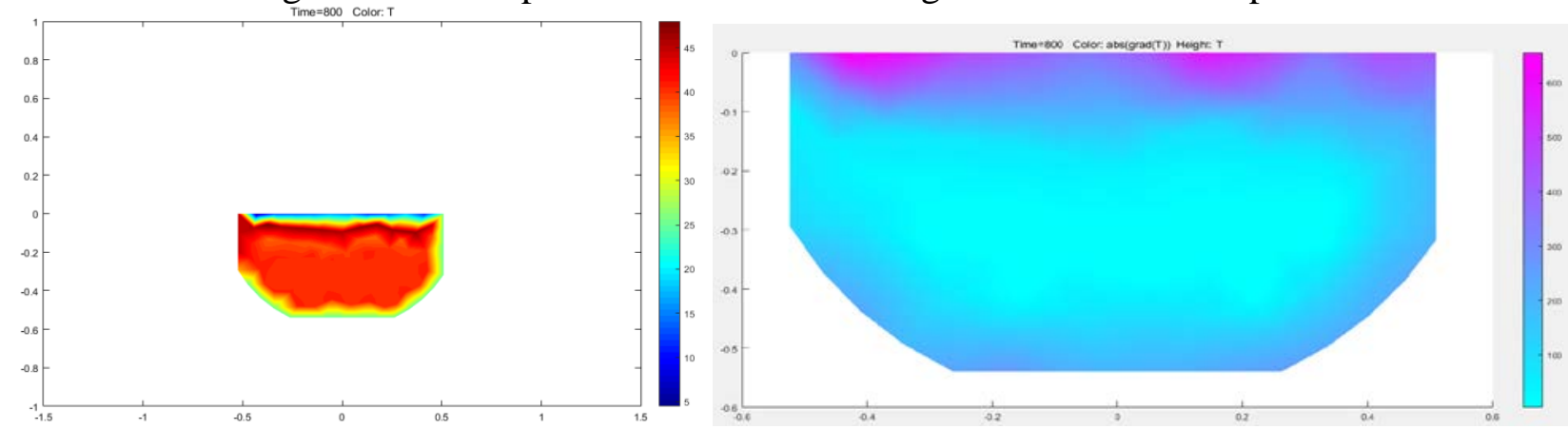

Figure 2: the temperature distribution and gradient on the Y-Z plane

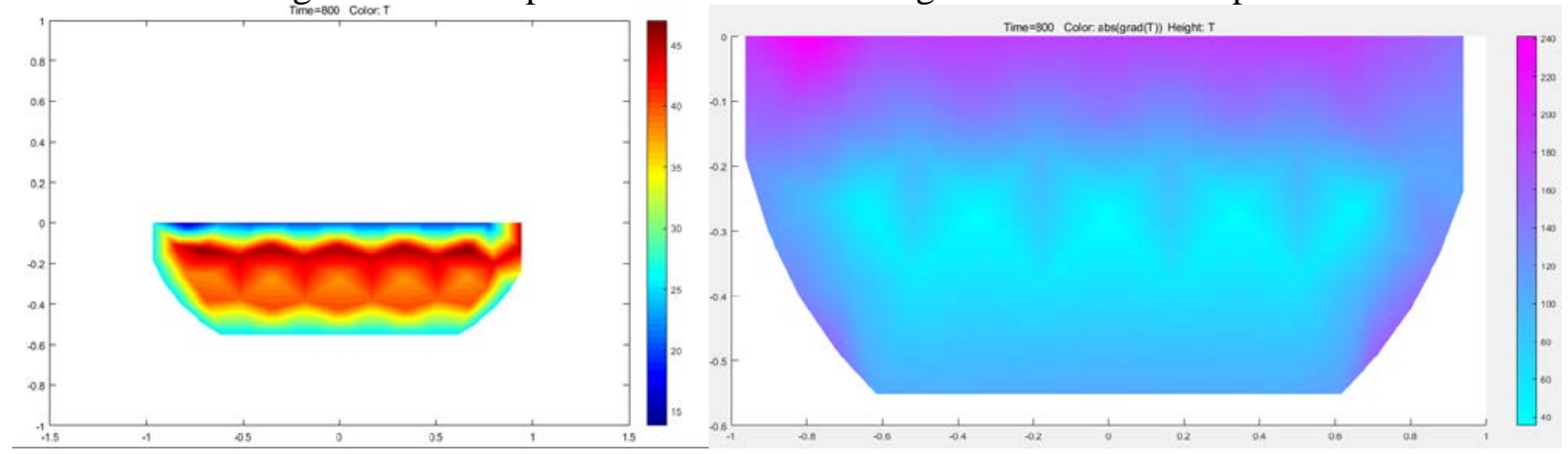

Figure 3: the temperature distribution and gradient on the $\mathrm{X}-\mathrm{Z}$ plane

The temperature distribution on the three plane
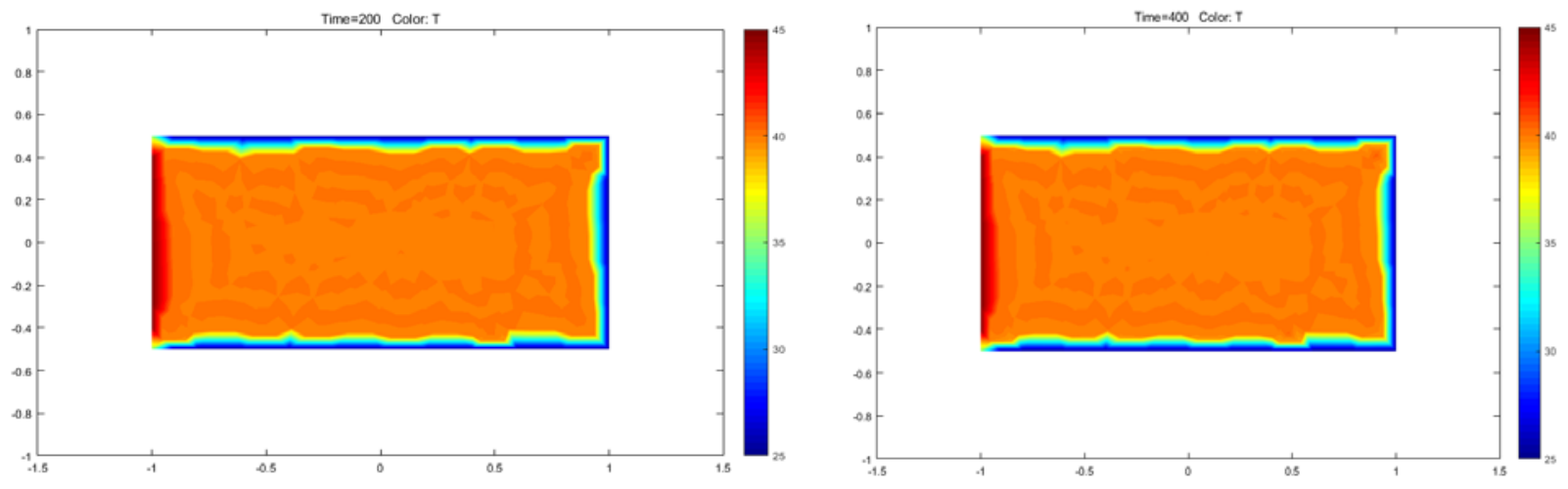

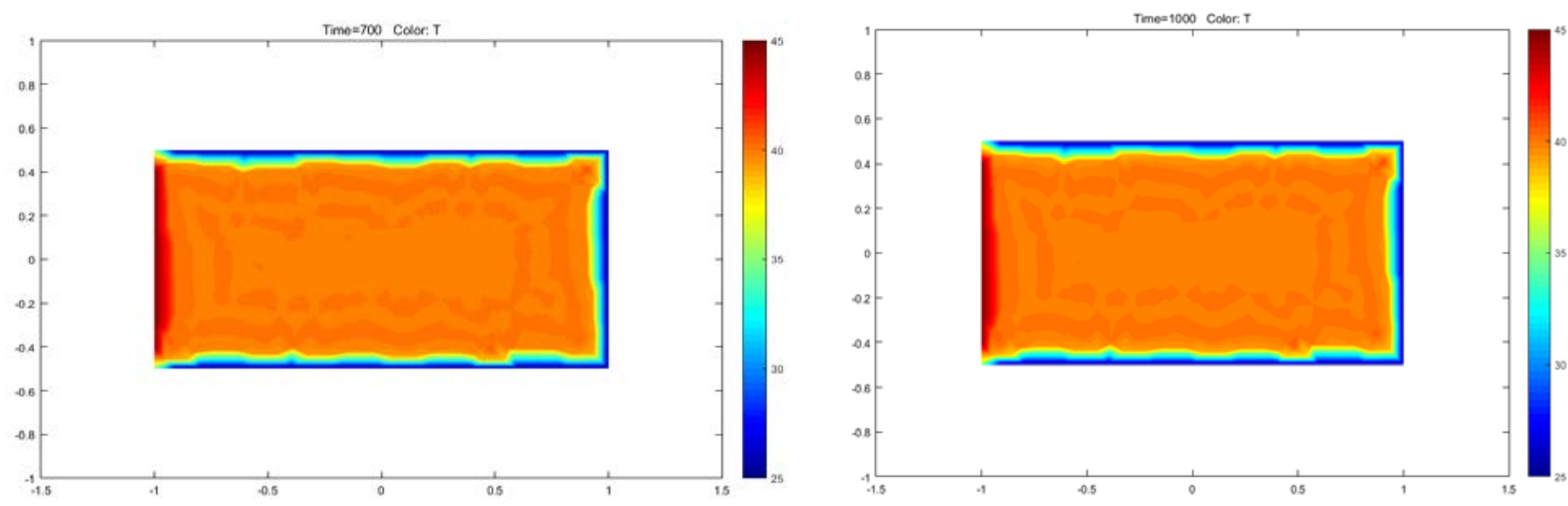

Figure 4: the temperature distribution of different time

\section{Conclusions}

We can find that under certain time scope and temperature terms both the variance of the temperature and the variance variation are very small, the temperature distribution of the bathtub basically doesn't vary with time.

\section{References}

[1] ShouKui Si XiJing Xun. Mathematical modeling algorithm and application. Beijing: National Defense Industry Press 2015.7

[2] ShengWei Yu. matlab mathematical modeling classic case of actual combat BeiJing Tsinghua University Press 2014. 